\title{
Journal of Geophysical Research: Biogeosciences
}

\author{
RESEARCH ARTICLE \\ 10.1002/2017JG004181 \\ Key Points: \\ - Temporal changes in temperature \\ sensitivity of lilac flowering date from \\ 1963 to 2013 were quantified \\ - Temperature sensitivity decreased \\ from 1963-1977 to 1999-2013 but \\ remained stable from 1963-1987 to \\ 1989-2013 \\ - Changes in temperature sensitivity \\ can be attributed to combined effects \\ of three driving factors
}

Correspondence to:

C. Wu and Q. Ge,

wucy@igsnrr.ac.cn;

geqs@igsnrr.ac.cn

\section{Citation:}

Wang, H., Dai, J., Rutishauser, T., Gonsamo, A., Wu, C., \& Ge, Q. (2018). Trends and variability in temperature sensitivity of lilac flowering phenology. Journal of Geophysical Research: Biogeosciences, 123, 807-817. https:// doi.org/10.1002/2017JG004181

Received 22 SEP 2017 Accepted 22 JAN 2018

Accepted article online 29 JAN 2018

Published online 11 MAR 2018

(c)2018. American Geophysical Union. All Rights Reserved.

\section{Trends and Variability in Temperature Sensitivity of Lilac Flowering Phenology}

\author{
Huanjiong Wang ${ }^{1}$ D, Junhu Dai ${ }^{1}$, This Rutishauser ${ }^{2}$ iD, Alemu Gonsamo ${ }^{3}$ iD, Chaoyang Wu ${ }^{1}$ iD, \\ and Quansheng $\mathbf{G e}^{1}$
}

${ }^{1}$ Key Laboratory of Land Surface Pattern and Simulation, Institute of Geographic Sciences and Natural Resources Research, Chinese Academy of Sciences, Beijing, China, ${ }^{2}$ Oeschger Centre for Climate Change Research (OCCR) and Institute of Geography, University of Bern, Bern, Switzerland, ${ }^{3}$ Department of Geography and Planning, University of Toronto, Toronto, Ontario, Canada

Abstract The responses of plant phenology to temperature variability have many consequences for ecological processes, agriculture, forestry, and human health. Temperature sensitivity $\left(S_{T}\right)$ of phenology could measure how and to what degree plant could phenologically track climate change. The long-term trends and spatial patterns in $S_{T}$ have been well studied for vegetative phenology such as leaf unfolding, but trends to be expected for reproductive phenology in the future remain unknown. Here we investigate trends and factors driving the temporal variation of $S_{T}$ of first bloom date (FBD). Using the long-term FBD records during 1963-2013 for common lilac (Syringa vulgaris) from 613 stations in Europe, we compared changes in $S_{T}$ from the beginning to the end of the study period. The Spearman partial correlations were used to assess the importance of four influencing factors. The results showed that the temporal changes in $S_{T}$ of FBD varied considerably among time scales. Mean $S_{T}$ decreased significantly by 0.92 days ${ }^{\circ} \mathrm{C}^{-1}$ from 1963-1972 to 2004-2013 ( $P<0.01$ ), but remained stable from 1963-1987 to 1989-2013. The strength of FBD and temperature relationship, the spring temperature variance, and winter chill all impact $S_{T}$ in an expected way at most stations. No consistent responses of $S_{T}$ on photoperiod were found. Our results imply that the trends and variability in $S_{T}$ of flowering phenology are driving by multiple factors and impacted by time scales. Continued efforts are still needed to further examine the flowering-temperature relationship for other plant species in other climates and environments using similar methods to our study.

\section{Introduction}

Phenology is the study of the timing of recurrent biological events, the causes of their timing regarding biotic and abiotic factors, and the interrelation among phases of the same or different species (Lieth, 1974). Phenological changes in response to climate change were widely reported. For example, most of spring plant phenophases such as leafing and flowering time became earlier across the globe over the past several decades (Chambers et al., 2013; Ge et al., 2015; Menzel, Sparks, Estrella, Koch, et al., 2006; Parmesan \& Yohe, 2003; Root et al., 2003; Schwartz, Ault, \& Betancourt, 2013), although the change in autumn phenophases was less apparent (Gill et al., 2015; Menzel, Sparks, Estrella, Koch, et al., 2006). These studies demonstrated that the plant phenophase is an important biological indicator of climate change impacts on terrestrial ecosystems (Rosenzweig et al., 2007). Interspecific differences lead to heterogeneous phenological responses and, for instance, to mismatch between plants and pollinators (Burkle et al., 2013; Hegland et al., 2008; Memmott et al., 2007) or between plants and animals from different trophic levels (Both et al., 2009; Edwards \& Richardson, 2004; Thackeray et al., 2010) and further impact ecosystem structure.

The direction of shifts in phenology in spring is dominated toward earlier appearances of plant phenophase in recent decades. The magnitude varies across species and depends on the species-specific temperature sensitivity $\left(S_{T}\right)$, which is defined as the change in phenological timing (in days) per ${ }^{\circ} \mathrm{C}$ increase. $S_{T}$ reflects how and to what degree species could phenologically track climate change. If species do not respond to climate change, they may be at a disadvantage because their growth becomes limited by missed interactions with mutualists or a shorter growing season relative to earlier active competitors (Cleland et al., 2012). In addition, if species have suffered damage from late spring frost, individuals with an earlier start of greening had a shorter period of recovery (Menzel, Helm, \& Zang, 2015). Observed 
evidence showed that species that do not respond to temperature had decreased considerably in abundance over the past 150 years (Willis et al., 2008). Invasive species exhibited strong temperature sensitivity of flowering time, which facilitated invasion at the community level (Willis et al., 2010). Cleland et al. (2012) assembled data for 57 species across 24 studies and found that species that advanced their phenology with warming increased their performance, including the production of biomass, fractional vegetation cover, and the number of flowers. All these pieces of evidence suggested that $S_{T}$ is related to species' ability to cope with global warming. Therefore, both observation and experimental studies paid close attention to the strength of $S_{T}$, although a significant difference between warming experiments and observational data had been reported (Wolkovich et al., 2012).

$S_{T}$ is neither constant among species/phases nor fixed across space. Earlier phenological events are more variable than later events (Bolmgren et al., 2013; Menzel, Sparks, Estrella, \& Roy, 2006) and exhibit the strongest reactions to temperature (Rosenzweig et al., 2007). Regarding spatial patterns, $S_{T}$ of flowering and leaf unfolding phases for several woody plants was significantly weaker at higher latitude or colder countries (Dai et al., 2014; Menzel, Sparks, Estrella, Koch, et al., 2006; H. Wang, Ge, Dai, et al., 2015). Such pattern was robust when using the satellite-derived start of vegetation growing season (Shen et al., 2014). The interspecific variations and spatial patterns in $S_{T}$ could be explained by the differences in the temperature at the onset date of phenophases and the base temperature threshold (H. Wang, Ge, Rutishauser, et al., 2015).

Furthermore, several studies investigated the changes in $S_{T}$ of spring leaf unfolding date over time or among different warming levels. The $S_{T}$ of leaf phenology of seven European species declined from a cold period (1980-1994) to a warm period (1999-2013), partly due to the reduced chilling (Fu et al., 2015). However, when comparing the difference in $S_{T}$ between 1951-1980 and 1984-2013 period, the $S_{T}$ of leaf phenology remained stable ( $\mathrm{H}$. Wang, Rutishauser, et al., 2017). The warming experiment using saplings of three woody plants showed that $S_{T}$ of leaf-out increased at low and moderate warming (Fu et al., 2013). Budburst phenology of several species responded to temperature in sigmoidal patterns (Caffarra \& Donnelly, 2011), suggesting that continued warming did not result in the further advancement of leaf unfolding.

Overall, the interspecific variations, long-term trends, and spatial patterns in $S_{T}$ have been well studied for vegetative phenology such as spring leaf unfolding, but trends to be expected for reproductive phenology in the future remain unknown. As such, the objective of this study is to address how $S_{T}$ of flowering phenology changed over the last five decades. In addition, there are several hypotheses to account for the changes in $S_{T}$ including the following: (1) Chilling requirement. Several studies demonstrated that the heat requirement of plants to initial leaf unfolding or flowering is negatively correlated with chilling conditions during dormancy period (Cannell \& Smith, 1983; Murray et al., 1989; Myking \& Heide, 1995). Warmer dormancy period would reduce the chill hours achieved, thus heat requirement would increase. As a result, the advance of spring phenophases under warming scenarios would slow down, causing a weaker $S_{T} ;(2)$ Photoperiod. Several studies pointed out that some plants would not develop until a long day length to avoid the potential risk of late frost (Körner \& Basler, 2010; Way \& Montgomery, 2015); (3) Spring temperature variance. Plants might be less likely to track climatic warming (exhibited weaker $S_{T}$ ) when spring temperature variance is high because the frost risk could be greater in a larger spring temperature variance and plants adapt to avoid this risk (Vitasse, Lenz, \& Koerner, 2014); (4) Correlation between first bloom date (FBD) and temperature. The correlation between FBD and temperature is a major factor impacting the estimate of $S_{T}(\mathrm{H}$. Wang, Rutishauser, et al., 2017). In an ecosystem limited by other factors (e.g., moisture), weak correlations between temperature and phenology may lead to a lower $S_{T}$. Considering the potential impacts of the above four factors, we also identified which factors are causing the actual changes in $S_{T}$.

Here using the long-term FBD records (1963-2013, time series $\geq 40$ years) of one lilac species in Central Europe, we calculated $S_{T}$ of FBD at 613 stations during different periods. Since the time scales may impact the estimate of $S_{T}\left(\mathrm{H}\right.$. Wang, Rutishauser, et al., 2017), we compared the changes in $S_{T}$ between periods with different lengths (10 years and 25 years). Subsequently, we compared the mean and standard deviation (SD) of $S_{T}$ based on random sampling methods to describe how $S_{T}$ varied among different time scales. Finally, partial correlation analysis was applied to assessing the relative importance of four potential factors in the variation of $S_{T}$ among periods. Furthermore, the application of these methods to other plant species in other climates could help to strengthen the understanding of the floweringtemperature relationship. 


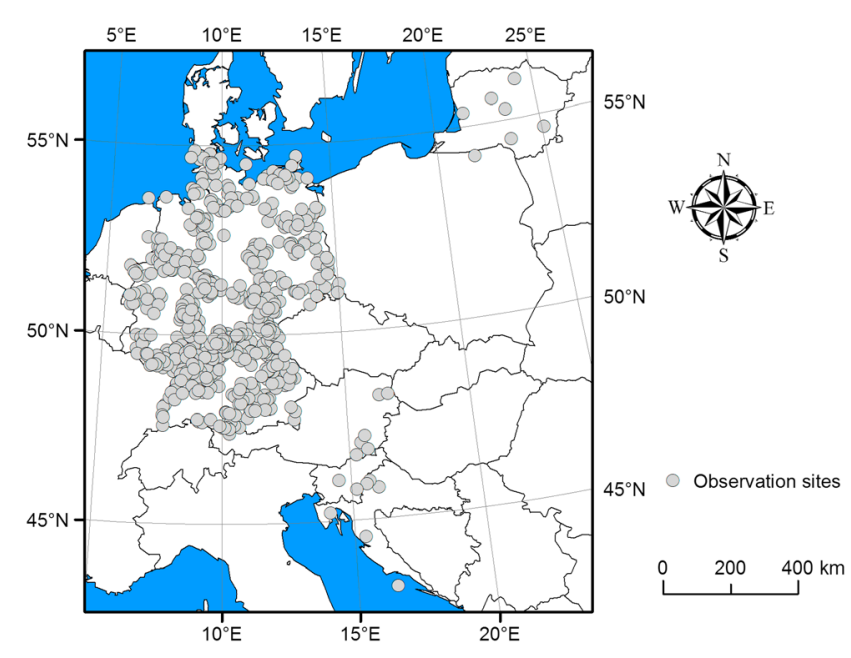

Figure 1. Locations of phenological observation stations for first bloom date time series ( $\geq 40$ years) of common lilac (Syringa vulgaris).

\section{Materials and Methods}

\subsection{Phenological and Meteorological Data}

We selected common lilac (Syringa vulgaris) to study the temporal variations in phenological response to temperature. Common lilac is a perennial, deciduous shrub belonging to genus Syringa. Because common lilac is widespread in Europe, their phenological responses can be evaluated over larger geographic areas than many other species. FBD, defined as the date of first flower opening (BBCH code: 60$)$ following the $\mathrm{BBCH}$ scheme (Meier, 2001), was chosen as a representative phenophase of spring.

Phenological records were provided by the members of the PEP725 project (PEP725, 2015). This database comprises observations of 121 plants and 46 development phases from national phenological networks across 26 European countries. We obtained the common lilac FBD data from 1963 to 2013 observed at 19,191 stations in Europe. Since the length of FBD time series should be sufficient for studying long-term changes in $S_{T}$, not all these stations were involved in the analysis, The criteria for selecting the phenological stations were as follows: (1) they had to contain at least 40 years of FBD data (except missing years) to ensure sufficient samples over time; (2) for each phenological station, a corresponding meteorological station must exist in the Global Historical Climatology Network (GHCN) data set. Meanwhile, distance and altitude difference between phenological and meteorological stations should be less than $40 \mathrm{~km}$ and $100 \mathrm{~m}$, respectively; (3) the corresponding meteorological stations had at least 40 years data within the observation period of FBD. As a result, our analyses consisted of 613 FBD time series in Central Europe (Figure 1).

The original phenological data were preprocessed by removing outliers since FBD in a few years surpassed its natural variability due to the errors that occur when noting or transcribing data (Schaber \& Badeck, 2002). For each FBD time series, observations were removed if the estimated residuals of linear models between FBD and years were larger than or equal to 30 days, as suggested by Schaber and Badeck (2002).

The daily maximum and minimum temperature data were obtained from the GHCN-Daily data set (Menne et al., 2012). The daily mean temperature was calculated as the arithmetic mean value of the maximum and minimum temperature. The GHCN-Daily data set integrates daily climate observations from approximately 30 different data sources and contains station-based measurements from well over 90,000 land-based stations worldwide. Among them, 87 climate stations corresponding to the phenological stations were selected according to the criteria mentioned above. Several phenological stations may share same meteorological data from an individual climate station.

\subsection{Methods}

\subsubsection{Estimating Temperature Sensitivity}

The $S_{T}$ of FBD was usually measured as the slope of linear regression between FBD and preseason temperature based on ordinary least squares estimation (Bock et al., 2014; Bolmgren et al., 2013; Dai et al., 2014; Fitter \& Fitter, 2002; Sparks et al., 2000). However, the ordinary linear regression is sensitive to outliers in the phenological data (Figure 2). Therefore, a robust method needs to be applied to plant phenological data (e.g., (Templ et al., 2017)). Nonparametric Theil-Sen estimator is a method for fitting a line to a set of points that chooses the median of the slopes of all lines through pairs of twodimensional sample points. Compared to the ordinary least squares estimation, no parametric Theil-Sen estimator has the advantages of simplicity in computation, analytical estimates of confidence
Figure 2. The Theil-Sen estimator of a set of observed first bloom dates and temperature with outliers compared to the nonrobust ordinary least squares line for the same set. 
intervals, robustness to outliers, testable assumptions regarding residuals, and requires limited a priori information regarding measurement errors (Fernandes \& Leblanc, 2005). Figure 2 shows an example of FBD-temperature relationship, and we can see that the Theil-Sen estimator is insensitive to outliers. Therefore, this study estimated $S_{T}$ as the Theil-Sen's slope of FBD against preseason temperature. The preseason at each station was defined as the period (with 5 day steps) before the mean FBD for which the Spearman's rank correlation coefficient between FBD and mean temperature was highest during 19632013 (H. Wang, Zhong, et al., 2017).

\subsubsection{Analyzing Temporal Changes in Temperature Sensitivity}

To study the temporal changes of $S_{T}$, we calculate the $S_{T}$ for the beginning and the end of the study period. The frequency distributions of $S_{T}$ across all species and stations for two 10 year periods (1963-1972 and 2004-2013) and 25 year periods (1963-1987 and 1989-2013) were determined. The differences in mean $S_{T}$ between two periods with the same length were tested using pair sample $t$ tests. For each station and period, at least half of FBD records need to be effective, and the stations with insufficient records will be excluded from the analyses.

To study the impacts of time scales on the estimate of $S_{T}$ at each station, we randomly resampled 10 and 25 years from the time series of FBD for 1,000 times and deleted repeated samples. Subsequently, we defined the preseason according to the methods mentioned above and calculated the $S_{T}$ using TheilSen estimator for each 10 year and 25 year sample at each station. The mean and SD of $S_{T}$ of all random samples were compared.

\subsubsection{Exploring Relative Importance of Potential Influencing Factors}

Subsequently, we performed partial correlation analysis between $S_{T}$ and the following four factors for 1,000 random samples. Spearman partial correlation coefficients between $S_{T}$ and each variable controlling for the remaining variables were calculated. The four variables mentioned in section 1 include the following:

1. Mean winter temperature. There are many methods to quantify the chilling conditions of plants, such as chilling hours model (Weinberger, 1950), Utah Model (Richardson et al., 1974), and so on. Usually, chilling accumulation is greater during a colder winter, regardless of which method is used. Therefore, we used the multiyear averaged winter (preceding December to February) temperature as the indicator of chilling conditions at each station.

2. Mean FBD. Due to the limitation of day length, FBD would not advance or slow down the advance when FBD became earlier enough. Thus, we listed mean FBD as a potential impacting factor.

3. Temperature SD. We used the multiyear averaged SD of daily temperature during the preseason to measure the spring temperature variance. The preseason here was consistent with that used for estimating temperature sensitivity.

4. Correlation between FBD and temperature. We use Pearson's coefficient between FBD and preseason temperature as a potential influencing factor.

The sign of partial correlation coefficient could reflect how each factor impacts $S_{T}$. According to the hypotheses mentioned in section 1 , the partial correlation coefficients of winter temperature $\left(R_{\text {winter_tem }}\right)$, temperature SD $\left(R_{\text {tem_SD }}\right)$, and the correlation between temperature and FBD $\left(R_{\text {corr }}\right)$ were expected to be positive, while the partial correlation coefficient of mean FBD ( $\left.R_{\text {mean_FBD }}\right)$ was expected to be negative. The frequency distribution of the sign and $P$ value of partial correlation coefficients across all stations was calculated to verify whether the response of $S_{T}$ was in accord with expectation.

\section{Results}

\subsection{Temporal Changes in Temperature Sensitivity}

The temporal changes in $S_{T}$ of FBD at all stations are summarized in Figure 3. On average, $S_{T}$ decreased significantly by $16.3 \%$ from -5.66 days ${ }^{\circ} \mathrm{C}^{-1}$ during $1963-1972$ (Figure 3a) to -4.74 days ${ }^{\circ} \mathrm{C}^{-1}$ during $2004-2013$ (Paired sample $t$ test, $P<0.01$, Figure $3 c$ ). The proportion of decreasing $S_{T}(64.1 \%)$ was larger than that of increasing $S_{T}$ (35.9\%, Figure 3e). However, when comparing the $S_{T}$ between 1963-1987 and 1989-2013, the proportion of decreasing $S_{T}(44.0 \%)$ was smaller than that of increasing $S_{T}$ (56.0\%, Figure 3f). The mean $S_{T}$ between these two periods was very close and not significantly different from zero $(-4.55$ versus -4.51 days ${ }^{\circ} \mathrm{C}^{-1}$, Paired sample $t$ test, $P>0.05$ ). 
10-year comparison
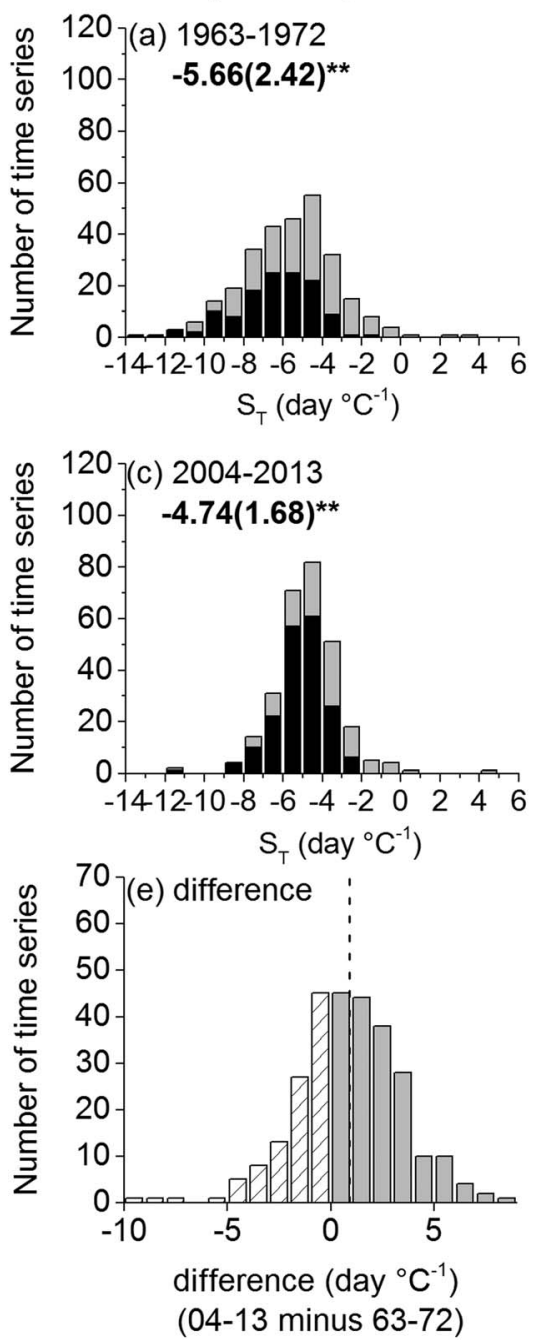

25-year comparison
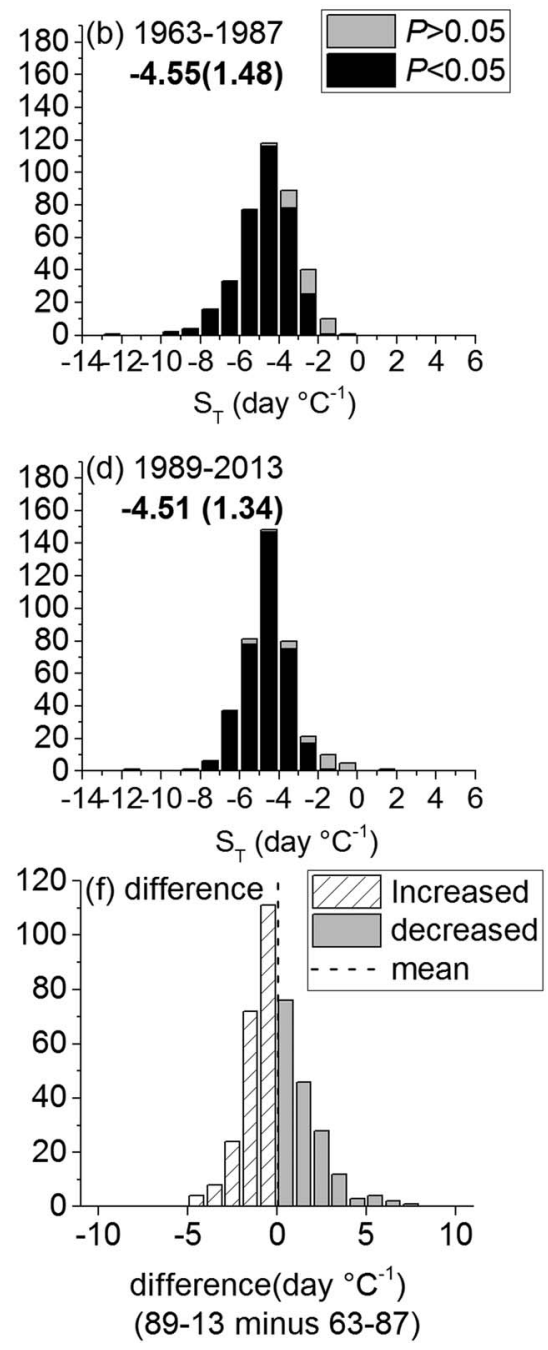

Figure 3. Changes in temperature sensitivity $\left(S_{T}\right)$ of lilac first bloom date over different time scales. Frequency distribution of $S_{T}$ across all sites during 1963-1972 (a), 2004-2013 (c), and the difference between these two 10 year periods (e). Frequency distribution of $S_{T}$ across all sites during 1963-1987 (b), 1989-2013 (d), and the difference between these two 25 year periods $(\mathrm{f}) * *: P<0.01$.

\subsection{Impact of Time Scale on Temperature Sensitivity Estimate}

For the 10 year random sampling method, mean $S_{T}$ of FBD ranged from -10.06 to -0.16 days ${ }^{\circ} \mathrm{C}^{-1}$ across stations and the overall mean $S_{T}$ was -5.38 days ${ }^{\circ} \mathrm{C}^{-1}$ (Figure 4a). For the 25 year random sampling method, the distribution of mean $S_{T}$ was similar with that of the 10 year random sampling method, and there was no significant difference between them $\left(5.38\right.$ versus 5.41 days $\left.{ }^{\circ} \mathrm{C}^{-1}\right)$. For the 10 year random sampling method, SD of $S_{T}$ ranged from 0.74 to 4.35 days ${ }^{\circ} \mathrm{C}^{-1}$ across stations with a mean of 1.74 days ${ }^{\circ} \mathrm{C}^{-1}$ (Figure $4 \mathrm{~b}$ ). For the 25 year random sampling method, the mean SD of $S_{T}\left(0.66\right.$ days $\left.{ }^{\circ} \mathrm{C}^{-1}\right)$ was significantly smaller than that of the 10 year random sampling method $(P<0.01, t$ test).

\subsection{Influencing Factors of Temperature Sensitivity}

The Spearman partial correlation coefficients between winter temperature and $S_{T}\left(R_{\text {winter_tem }}\right)$ were expected to be positive. The $63.3 \%$ (41.3\% significantly) and $60.5 \%$ (39.7\% significantly) of $R_{\text {winter_tem values were in }}$ accord with expectation for the 10 year and 25 year random sampling methods, respectively (Figures $5 \mathrm{a}$ and $5 \mathrm{e}$ ). The mean value of $R_{\text {winter_tem }}(0.037$ and 0.038$)$ was significantly greater than zero for both time scales (one sample $t$ test, $P<0.01$ ). 

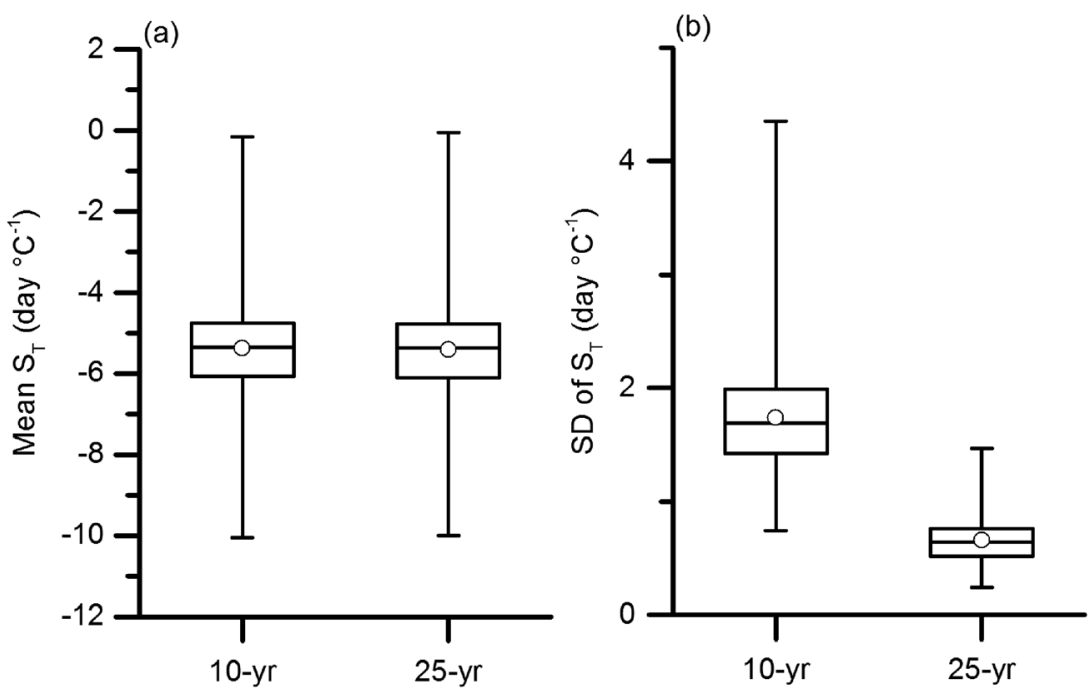

Figure 4. Mean (a) and standard deviation (b) of $S_{T}$ among different 10 year and 25 year random samples at each station. Bottoms and tops of boxes $=25$ th and 75 th percentiles; bands within boxes = medians; whiskers $=$ minimum and maximum; circles = mean value over all stations.

Regarding the mean FBD, the partial correlation coefficients ( $\left.R_{\text {mean_FBD }}\right)$ were expected to be negative. Our result showed that only $36.7 \%$ ( $27.9 \%$ significantly) and $38.5 \%$ (30.6\% significantly) of $R_{\text {mean_FBD values were }}$ as expected for the 10 year and 25 year random sampling methods, respectively (Figures $5 \mathrm{~b}$ and $5 \mathrm{f}$ ). The mean values of $R_{\text {mean_FBD }}$ were not significantly less than zero for both methods (one sample $t$ test).

Concerning the SD of preseason temperature, $77.1 \%$ and $76.6 \%$ of the partial correlation coefficients $\left(R_{\text {tem_sD }}\right)$ were in an expected sign (positive) for the 10 year and 25 year random sampling methods, respectively (Figures $5 \mathrm{c}$ and $5 \mathrm{~g}$ ). In addition, more than $63 \%$ of $R_{\text {tem_SD }}$ values were significant at $P<0.05$. The mean

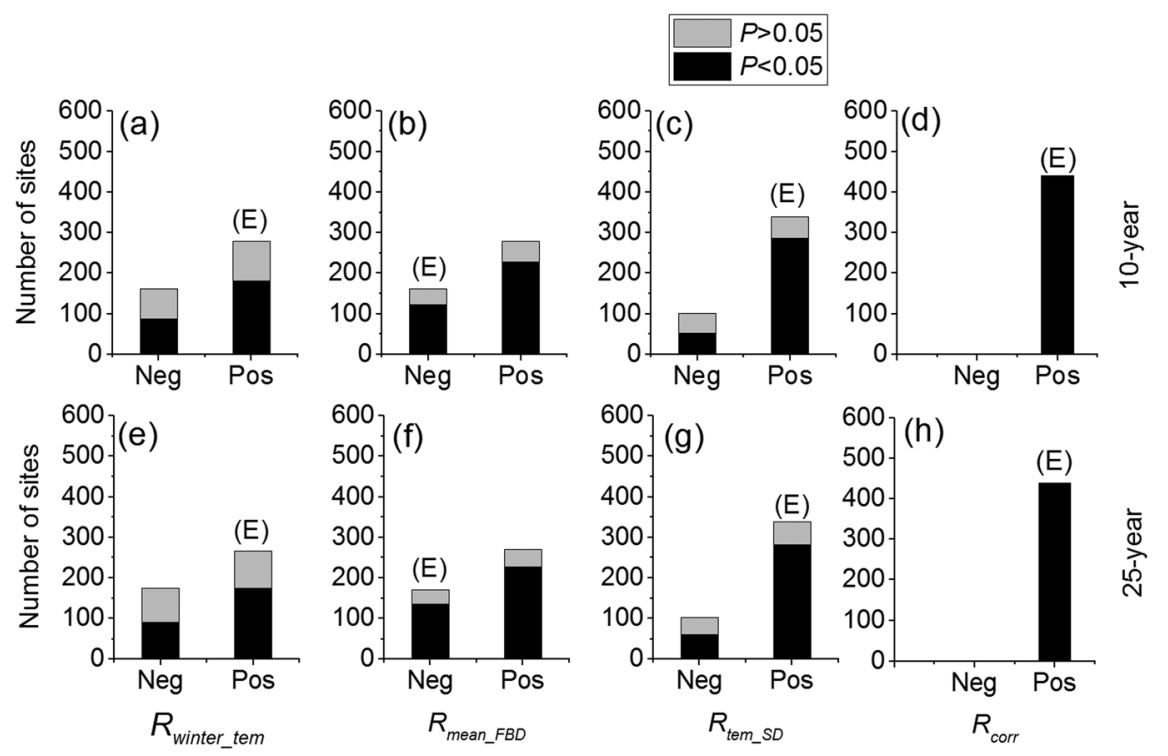

Figure 5. Spearman partial correlation coefficients between temperature sensitivity of lilac first bloom date (FBD) and four potential factors. The first and second rows represent the results from 10 year and 25 year random sampling method, respectively. Four columns showed the number of negative (Neg) and positive (Pos) partial correlation coefficients of winter temperature $\left(R_{\text {winter_tem }}\right)$, mean FBD $\left(R_{\text {mean_FBD }}\right)$, the standard deviation of preseason temperature $\left(R_{\text {tem_sD }}\right)$, and Pearson's $R$ between FBD and temperature $\left(R_{\text {corr }}\right)$, respectively. Black color represented significant correlation coefficients $(P<0.05)$. The character $(E)$ above the bars indicated that the sign was in accordance with expectation. 
Winter temperature

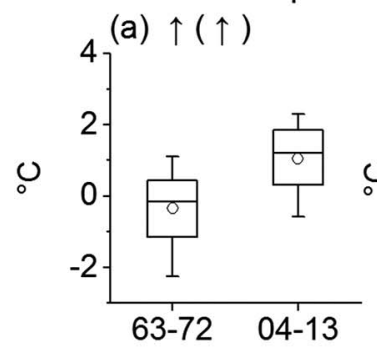

(d) $\uparrow(\uparrow)$

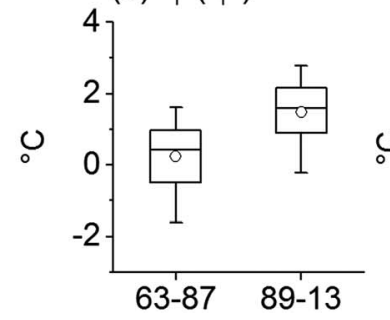

Temperature SD

(b) $\downarrow(\downarrow)$

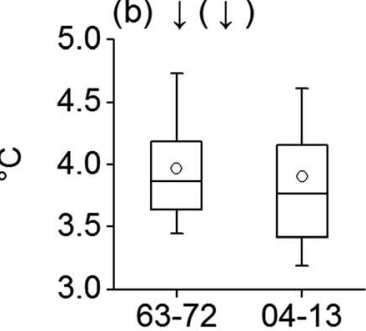

(e) $\uparrow(\uparrow)$

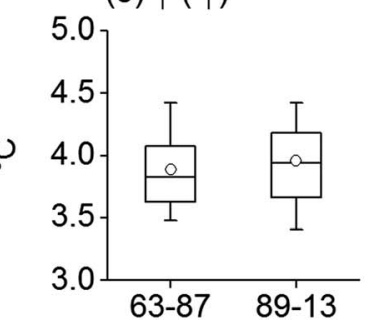

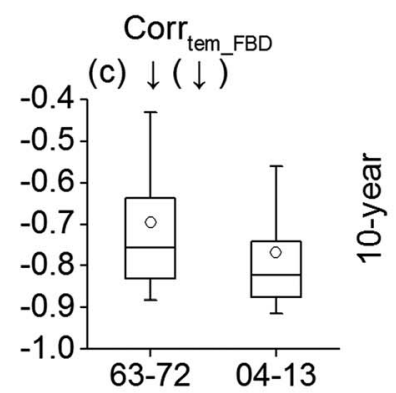

(f) $\downarrow(\downarrow)$

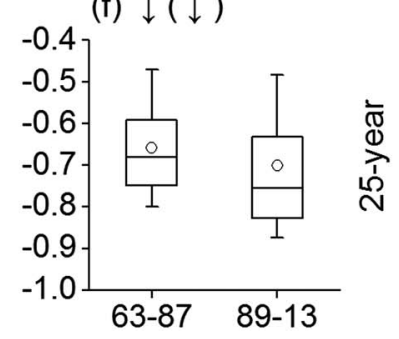

Figure 6. Changes in three primary factors impacting temperature sensitivity of lilac first bloom date. Different factors are shown in each column. Arrows (downward: decrease; upward: increase) indicate the significant difference between periods (Pair-sample $t$ test, $P<0.01$ ). The arrows in bracket indicate that the change in this factor will lead to increased (downward) or decreased (upward) temperature sensitivity. Bottoms and tops of boxes $=25$ th and 75th percentiles; bands within boxes = medians; whiskers $=10$ th and 90th percentiles; circles = mean value.

value of $R_{\text {tem_SD }}(0.11$ and 0.12$)$ averaged from all stations were significantly greater than zero for both methods (one sample $t$ test, $P<0.01$ ).

With regard to the Pearson's $R$ between FBD and preseason temperature, the sign of the partial correlation coefficients $\left(R_{\text {corr }}\right)$ showed a clear pattern (Figures $5 \mathrm{~d}$ and $5 \mathrm{~h}$ ). Of the $R_{\text {corr }}$ values, $100 \%$ and $99.5 \%$ were significant and in an expected sign (positive) for the 10 year and 25 year random sampling methods, respectively. Furthermore, the mean values of $R_{\text {corr }}(0.49$ and 0.51$)$ averaged from all stations were significantly greater than zero for both methods (one sample $t$ test, $P<0.01$ ).

Overall, except mean FBD, other three factors showed relatively consistent impacts on $S_{T}$ of lilac FBD. The most important one is Pearson's $R$ between phenophase and temperature, followed by the spring temperature variance and winter chill. A stronger relationship between spring phenology and preseason temperature and lower spring temperature variance tend to cause stronger $S_{T}$, while less winter chill tends to lead to weaker $S_{T}$.

\subsection{Temporal Changes in Primary Factors}

In order to identify which factors are causing the actual changes in $S_{T}$, we compared the changes in three primary factors between periods (Figure 6). The result showed that the decreased $S_{T}$ from 1963-1972 to 2004-2013 could be attributed to reduced winter chill (warmer winter temperature) during the latter period, although the lower temperature variances and the increased strength of temperature-FBD relationship exert an increased effect on $S_{T}$. When comparing the $S_{T}$ between 1963-1987 and 1989-2013, the effect of reduced winter chill and stronger temperature variance was offset by the effect of stronger temperature-FBD relationship. These results suggested that the actual effect of the strength of temperature-FBD relationship on $S_{T}$ varied among time scales. On longer time scale (25 years), the effect of the strength of temperature-FBD relationship became stronger and then caused a stable $S_{T}$.

\section{Discussion}

$S_{T}$ of lilac FBD varied significantly between 1963-1972 and 2004-2013 period (Figure 3). This result was consistent with previous findings. For example, in Beijing, China, the responsiveness of FBD of 48 woody plants to temperature change during the period 1990-2007 was significantly stronger than the preceding period 


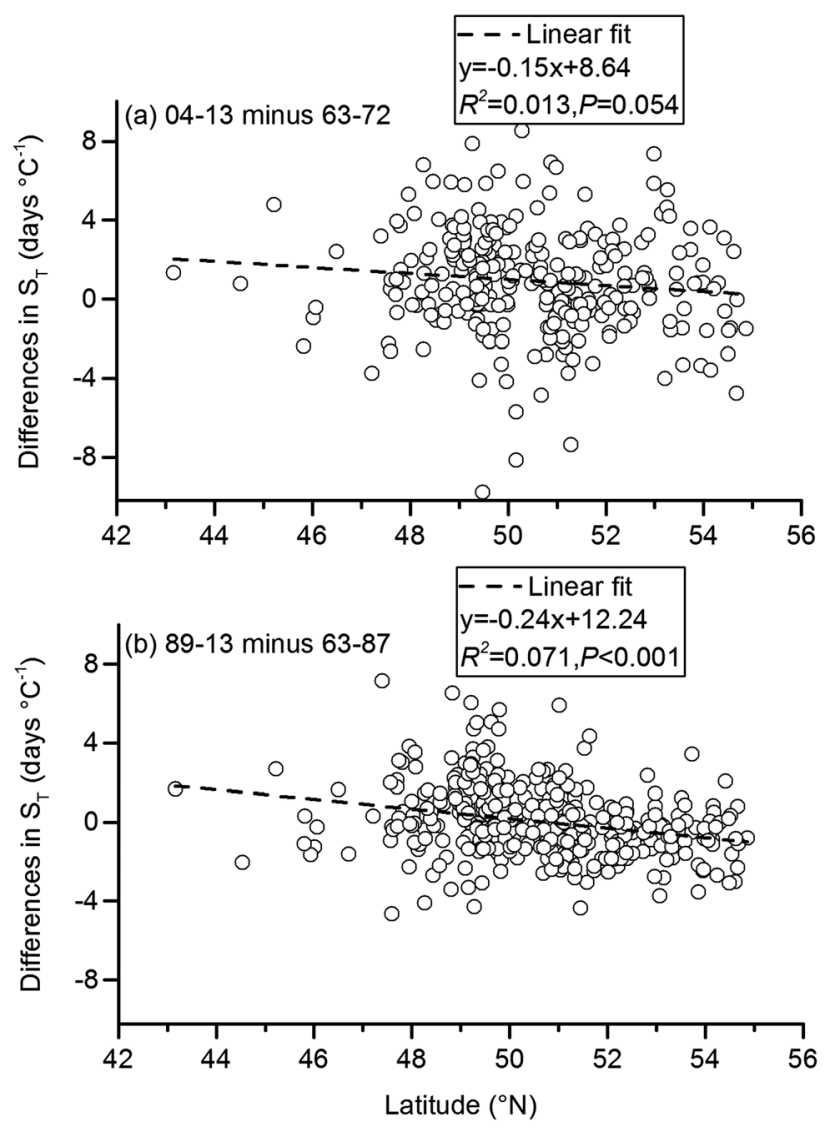

Figure 7. Changes in temperature sensitivity of lilac first bloom date $\left(S_{T}\right)$ at all stations plotted according to latitude. (a) The difference in $S_{T}$ between 1963-1972 and 2004-2013; (b) the difference in $S_{T}$ between 1963-1987 and 1989-2013.
1963-1989 (Bai et al., 2011). $S_{T}$ of spring plant phenology was also unstable in the United Kingdom $\left(-15\right.$ to -2 days $\left.{ }^{\circ} \mathrm{C}^{-1}\right)$ and Switzerland $\left(-5\right.$ to -2.5 days ${ }^{\circ} \mathrm{C}^{-1}$ ) from 1973 to 1958 among different 30 year periods (Rutishauser et al., 2009). However, for three plant species (including common lilac) observed at eight stations in Germany, the response rates of flowering onset to variations in temperature did not differ significantly between the first and the second half of the twentieth century (Menzel, Estrella, \& Testka, 2005). This result was consistent with our finding that there was no significant difference in the $S_{T}$ of lilac FBD between 1963-1987 and 1989-2013. Therefore, the changes in $S_{T}$ depend on time scales adopted.

Furthermore, the temporal changes in the $S_{T}$ of lilac FBD varied greatly among stations. There are considerable proportions of increasing and decreasing changes in $S_{T}$ from the beginning to the end of the study period (Figures $3 e$ and $3 f$ ). Although the changes in $S_{T}$ correlated negatively with latitude, latitude could only explain a small percentage (1.3\% or $7.1 \%$ ) of variance (Figure 7). Thus, the changes in $S_{T}$ exhibited strong spatial heterogeneity.

Theoretically, the magnitude of phenological variability relative to temperature variability determines the $S_{T}$ of phenophases. However, this is established on the correlation between phenophase and temperature. If Pearson's $R$ between phenophase and temperature became weaker, the estimate of $S_{T}$ tends to be zero. Our result demonstrated that Pearson's $R$ impacted $S_{T}$ in an expected direction at more than $99 \%$ of the stations. This result suggested that Pearson's $R$ is the most important factor impacting the estimate of $S_{T}$. The Pearson's $R$ between phenology and temperature was more unstable among the 10 year samples compared to the 25 year samples (results not shown). The possible reason was that the estimate of $S_{T}$ based on short records with narrow time window might be impacted by systematic or random errors from the replacement of observers or observation criteria in the accumulative process of phenological data (H. Wang, Rutishauser, et al., 2017).

Most of the stations (more than 76\%) showed that the $S_{T}$ of lilac FBD tended to decline during the period with more fluctuating preseason temperature. This suggested that the magnitude of the variability of temperature during the preseason was an essential factor affecting the $S_{T}$ of spring phenology. A possible mechanism was that plants weaken their phenological response to avoid frost risk in the climate with a higher variance of spring temperature. Our results were also consistent with the impact of temperature SD on $S_{T}$ across space. In Europe, declining $S_{T}$ of spring phases was associated with larger local spring temperature SD for 25 species (T. Wang et al., 2014). Similarly, plants at sites with higher temperature variability exhibited lower $S_{T}$ in China (Zhang et al., 2015). However, Fu et al. (2015) reported that altered temperature variance was not an apparent cause of the changes in $S_{T}$. This is because they just selected two distinct periods to compare the difference in $S_{T}$ and spring temperature SD. When examining the relation between $S_{T}$ and spring temperature SD among 1,000 random samples, the effect of temperature variance on $S_{T}$ would be apparent.

As mentioned above, the increased winter temperature may make plants need more forcing temperatures to flower in spring, thus weaken the $S_{T}$. This hypothesis is true at about $60 \%$ of the stations. Therefore, winter chilling is a considerable control mechanism for changes in $S_{T}$. However, there are about $40 \%$ of the stations that showed opposite results. The possible reason was that lilac species require only a minor chilling for flowering (Schwartz \& Hanes, 2010) and their chilling requirement is easy to be satisfied, especially in cold regions. For other species requiring more chilling hours, winter temperature may significantly affect spring phenology. The role of winter chilling in spring phenology is still under debate (Chuine et al., 2010). 
For plant species sensitive to photoperiod, photoperiod might prohibit a too early start of the growing season in an extremely warm year. Therefore, if FBD became earlier, $S_{T}$ was expected to be weaker. However, only at about $30 \%$ of the stations, the $S_{T}$ responded to mean FBD in an expected direction. At other stations, $S_{T}$ even became stronger when FBD became earlier. Therefore, there were no consistent signals of photoperiod limitation on FBD. The possible reason was that lilac species are photoperiod-insensitive (Körner \& Basler, 2010). Therefore, we could not exclude photoperiod as an influencing factor of $S_{T}$ for other plant species.

In this study, we only analyzed four potential factors impacting the estimate of $S_{T}$. However, other influencing factors of $S_{T}$ also existed, including changes in tree age, nonlinear responses of plant development to temperature, and microclimate (Menzel et al., 2005; Vitasse, 2013; H. Wang, Rutishauser, et al., 2017). In the future, if we could manipulate environmental factors separately through experiments, the relative importance of individual factor or the interaction effect of several factors on the $S_{T}$ of plant phenology could be determined. In addition, we only tested one lilac species in this study. For other species, the roles of all potential factors in affecting spring phenology remain unclear. We suggest that continued efforts that are directed toward investigating temporal changes in $S_{T}$ use methods similar to our study for additional species of interest.

In summary, using lilac flowering data (1963-2013) at 613 stations in Europe, this study demonstrated that trends and variability in the $S_{T}$ of flowering phenology depend on time scales. Mean $S_{T}$ decreased significantly by 0.92 days ${ }^{\circ} \mathrm{C}^{-1}$ from $1963-1972$ to $2004-2013(P<0.01)$, but remained stable from $1963-1987$ to 1989-2013. From the beginning to the end of the study period, a stronger temperature-FBD relationship tends to cause stronger $S_{T}$, while less winter chill tends to lead to weaker $S_{T}$. The effect of the strength of temperature-FBD relationship on $S_{T}$ became stronger on longer time scales and caused stable $S_{T}$ between two 25 year periods (1963-1987 and 1989-2013). Since species with weaker phenological sensitivity to temperature may be at a disadvantage if their growth becomes limited by missed interactions with mutualists, or a shorter growing season relative to earlier-active competitors (Cleland et al., 2012), continuous and longterm phenological monitoring is still needed to improve sensitivity estimate on different time scales.

Acknowledgments

The data used are listed in the references. This research was supported by the Key Research Program of Frontier Sciences, CAS (QYZDB-SSW-DQC011) and National Natural Science Foundation of China (41601047 and 41427805).

\section{References}

Bai, J., Ge, Q., \& Dai, J. (2011). The response of first flowering dates to abrupt climate change in Beijing. Advances in Atmospheric Sciences, 28(3), 564-572. https://doi.org/10.1007/s00376-010-9219-8

Bock, A., Sparks, T. H., Estrella, N., Jee, N., Casebow, A., Schunk, C., et al. (2014). Changes in first flowering dates and flowering duration of 232 plant species on the island of Guernsey. Global Change Biology, 20(11), 3508-3519. https://doi.org/10.1111/gcb.12579

Bolmgren, K., Vanhoenacker, D., \& Miller-Rushing, A. J. (2013). One man, 73 years, and 25 species. Evaluating phenological responses using a lifelong study of first flowering dates. International Journal of Biometeorology, 57(3), 367-375. https://doi.org/10.1007/s00484-012-0560-8

Both, C., Van Asch, M., Bijlsma, R. G., Van Den Burg, A. B., \& Visser, M. E. (2009). Climate change and unequal phenological changes across four trophic levels: Constraints or adaptations? Journal of Animal Ecology, 78(1), 73-83. https://doi.org/10.1111/j.1365-2656.2008.01458.x

Burkle, L. A., Marlin, J. C., \& Knight, T. M. (2013). Plant-pollinator interactions over 120 years: Loss of species, co-occurrence, and function. Science, 339(6127), 1611-1615. https://doi.org/10.1126/science.1232728

Caffarra, A., \& Donnelly, A. (2011). The ecological significance of phenology in four different tree species: Effects of light and temperature on bud burst. International Journal of Biometeorology, 55(5), 711-721. https://doi.org/10.1007/s00484-010-0386-1

Cannell, M. G. R., \& Smith, R. I. (1983). Thermal time, chill days and prediction of budburst in Picea sitchensis. Journal of Applied Ecology, 20(3), 951-963. https://doi.org/10.2307/2403139

Chambers, L. E., Altwegg, R., Barbraud, C., Barnard, P., Beaumont, L. J., Crawford, R. J. M., et al. (2013). Phenological changes in the Southern Hemisphere. PLoS One, 8(10), e75514. https://doi.org/10.1371/journal.pone.0075514

Chuine, I., Morin, X., \& Bugmann, H. (2010). Warming, photoperiods, and tree phenology. Science, 329(5989), 277-278. https://doi.org/ 10.1126/science.329.5989.277-e

Cleland, E. E., Allen, J. M., Crimmins, T. M., Dunne, J. A., Pau, S., Travers, S. E., et al. (2012). Phenological tracking enables positive species responses to climate change. Ecology, 93(8), 1765-1771. https://doi.org/10.1890/11-1912.1

Dai, J., Wang, H., \& Ge, Q. (2014). The spatial pattern of leaf phenology and its response to climate change in China. International Journal of Biometeorology, 58(4), 521-528. https://doi.org/10.1007/s00484-013-0679-2

Edwards, M., \& Richardson, A. J. (2004). Impact of climate change on marine pelagic phenology and trophic mismatch. Nature, 430(7002), 881-884. https://doi.org/10.1038/nature02808

Fernandes, R., \& Leblanc, S. G. (2005). Parametric (modified least squares) and non-parametric (Theil-Sen) linear regressions for predicting biophysical parameters in the presence of measurement errors. Remote Sensing of Environment, 95(3), 303-316. https://doi.org/10.1016/ j.rse.2005.01.005

Fitter, A. H., \& Fitter, R. (2002). Rapid changes in flowering time in British plants. Science, 296(5573), 1689-1691. https://doi.org/10.1126/ science. 1071617

Fu, Y. H., Campioli, M., Deckmyn, G., \& Janssens, I. A. (2013). Sensitivity of leaf unfolding to experimental warming in three temperate tree species. Agricultural and Forest Meteorology, 181, 125-132. https://doi.org/10.1016/j.agrformet.2013.07.016

Fu, Y. H., Zhao, H., Piao, S., Peaucelle, M., Peng, S., Zhou, G., et al. (2015). Declining global warming effects on the phenology of spring leaf unfolding. Nature, 526(7571), 104-107. https://doi.org/10.1038/nature15402

Ge, Q., Wang, H., Rutishauser, T., \& Dai, J. (2015). Phenological response to climate change in China: A meta-analysis. Global Change Biology, 21(1), 265-274. https://doi.org/10.1111/gcb.12648 
Gill, A. L., Gallinat, A. S., Sanders-DeMott, R., Rigden, A. J., Gianotti, D. J. S., Mantooth, J. A., \& Templer, P. H. (2015). Changes in autumn senescence in Northern Hemisphere deciduous trees: A meta-analysis of autumn phenology studies. Annals of Botany, 116(6), 875-888. https://doi.org/10.1093/aob/mcv055

Hegland, S. J., Nielsen, A., Lazaro, A., Bjerknes, A. L., \& Totland, O. (2008). How does climate warming affect plant-pollinator interactions? Ecology Letters, 12(2), 184-195. https://doi.org/10.1111/j.1461-0248.2008.01269.x

Körner, C., \& Basler, D. (2010). Phenology under global warming. Science, 327(5972), 1461-1462. https://doi.org/10.1126/science.1186473

Lieth, H. (1974). Phenology and seasonality modelling. Berlin: Springer. https://doi.org/10.1007/978-3-642-51863-8

Meier, U. (2001). Growth stages of mono-and dicotyledonous plants: BBCH monograph (2nd ed.). Berlin: Federal Biological Research Centre for Agriculture and Forestry.

Memmott, J., Craze, P. G., Waser, N. M., \& Price, M. V. (2007). Global warming and the disruption of plant-pollinator interactions. Ecology Letters, 10(8), 710-717. https://doi.org/10.1111/j.1461-0248.2007.01061.x

Menne, M. J., Durre, I., Korzeniewski, B., McNeal, S., Thomas, K., Yin, X., et al. (2012). Global Historical Climatology Network-daily (GHCN-daily), version 3, NOAA National Climatic Data Center. https://doi.org/10.7289/V5D21VHZ (Accessed at 01 August 2017).

Menzel, A., Estrella, N., \& Testka, A. (2005). Temperature response rates from long-term phenological records. Climate Research, 30(1), 21-28. https://doi.org/10.3354/cr030021

Menzel, A., Helm, R., \& Zang, C. (2015). Patterns of late spring frost leaf damage and recovery in a European beech (Fagus sylvatica L.) stand in south-eastern Germany based on repeated digital photographs. Frontiers in Plant Science, 6, 110. https://doi.org/10.3389/fpls.2015.00110

Menzel, A., Sparks, T. H., Estrella, N., Koch, E., Aasa, A., Ahas, R., et al. (2006). European phenological response to climate change matches the warming pattern. Global Change Biology, 12(10), 1969-1976. https://doi.org/10.1111/j.1365-2486.2006.01193.x

Menzel, A., Sparks, T. H., Estrella, N., \& Roy, D. B. (2006). Altered geographic and temporal variability in phenology in response to climate change. Global Ecology and Biogeography, 15(5), 498-504. https://doi.org/10.1111/j.1466-822X.2006.00247.x

Murray, M. B., Cannell, M., \& Smith, R. I. (1989). Date of budburst of fifteen tree species in Britain following climatic warming. Journal of Applied Ecology, 26(2), 693-700. https://doi.org/10.2307/2404093

Myking, T., \& Heide, O. M. (1995). Dormancy release and chilling requirement of buds of latitudinal ecotypes of Betula pendula and B. pubescens. Tree Physiology, 15(11), 697-704. https://doi.org/10.1093/treephys/15.11.697

Parmesan, C., \& Yohe, G. (2003). A globally coherent fingerprint of climate change impacts across natural systems. Nature, 421(6918), 37-42. https://doi.org/10.1038/nature01286

PEP725 (2015). Pan European phenology data. Retrieved from http://www.pep725.eu/. (Accessed at 01 August 2017).

Richardson, E. A., Seeley, S. D., \& Walker, D. R. (1974). A model for estimating the completion of rest for Redhaven and Elberta peach trees. Hortscience, 9(4), 331-332.

Root, T. L., Price, J. T., Hall, K. R., Schneider, S. H., Rosenzweig, C., \& Pounds, J. A. (2003). Fingerprints of global warming on wild animals and plants. Nature, 421(6918), 57-60. https://doi.org/10.1038/nature01333

Rosenzweig, C., Casassa, G., Karoly, D. J., Imeson, A., Liu, C., Menzel, A., et al. (2007). Assessment of observed changes and responses in natura and managed systems. In M. L. Parry, et al. (Eds.), Climate change 2007: Impacts, adaptation and vulnerability. Contribution of Working Group II to the Fourth Assessment Report of the Intergovernmental Panel on Climate Change (pp. 79-131). Cambridge: Cambridge University Press.

Rutishauser, T., Schleip, C., Sparks, T., Nordli, O., Menzel, A., Wanner, H., et al. (2009). Temperature sensitivity of Swiss and British plant phenology from 1753 to 1958 . Climate Research, 39, 179-190. https://doi.org/10.3354/cr00810

Schaber, J., \& Badeck, F. W. (2002). Evaluation of methods for the combination of phenological time series and outlier detection. Tree Physiology, 22(14), 973-982. https://doi.org/10.1093/treephys/22.14.973

Schwartz, M. D., Ault, T. R., \& Betancourt, J. L. (2013). Spring onset variations and trends in the continental United States: Past and regional assessment using temperature-based indices. International Journal of Climatology, 33(13), 2917-2922. https://doi.org/10.1002/ joc.3625

Schwartz, M. D., \& Hanes, J. M. (2010). Continental-scale phenology: Warming and chilling. International Journal of Climatology, 30(11), 1595-1598. https://doi.org/10.1002/joc.2014

Shen, M., Tang, Y., Chen, J., Yang, X., Wang, C., Cui, X., et al. (2014). Earlier-season vegetation has greater temperature sensitivity of spring phenology in Northern Hemisphere. PLoS One, 9(2), e88178. https://doi.org/10.1371/journal.pone.0088178

Sparks, T. H., Jeffree, E. P., \& Jeffree, C. E. (2000). An examination of the relationship between flowering times and temperature at the national scale using long-term phenological records from the UK. International Journal of Biometeorology, 44(2), 82-87. https://doi.org/10.1007/ s004840000049

Templ, B., Templ, M., Filzmoser, P., Lehoczky, A., Bakšienè, E., FleckHilppa, S., et al. (2017). Phenological patterns of flowering across biogeographical regions of Europe. International Journal of Biometeorology, 61(7), 1347-1358. https://doi.org/10.1007/s00484-017-1312-6

Thackeray, S. J., Sparks, T. H., Frederiksen, M., Burthe, S., Bacon, P. J., Bell, J. R., et al. (2010). Trophic level asynchrony in rates of phenological change for marine, freshwater and terrestrial environments. Global Change Biology, 16(12), 3304-3313. https://doi.org/10.1111/ j.1365-2486.2010.02165.x

Vitasse, Y. (2013). Ontogenic changes rather than difference in temperature cause understory trees to leaf out earlier. New Phytologist, 198(1), 149-155. https://doi.org/10.1111/nph.12130

Vitasse, Y., Lenz, A., \& Koerner, C. (2014). The interaction between freezing tolerance and phenology in temperate deciduous trees. Frontiers in Plant Science, 6(UNSP 541), 541. https://doi.org/10.3389/fpls.2014.00541

Wang, H., Ge, Q., Dai, J., \& Tao, Z. (2015). Geographical pattern in first bloom variability and its relation to temperature sensitivity in the USA and China. International Journal of Biometeorology, 59(8), 961-969. https://doi.org/10.1007/s00484-014-0909-2

Wang, H., Ge, Q., Rutishauser, T., Dai, Y., \& Dai, J. (2015). Parameterization of temperature sensitivity of spring phenology and its application in explaining diverse phenological responses to temperature change. Scientific Reports, 5(1), 8833. https://doi.org/10.1038/ srep08833

Wang, T., Ottlé, C., Peng, S., Janssens, I. A., Lin, X., Poulter, B., et al. (2014). The influence of local spring temperature variance on temperature sensitivity of spring phenology. Global Change Biology, 20(5), 1473-1480. https://doi.org/10.1111/gcb.12509

Wang, H., Rutishauser, T., Tao, Z., Zhong, S., Ge, Q., \& Dai, J. (2017). Impacts of global warming on phenology of spring leaf unfolding remain stable in the long run. International Journal of Biometeorology, 61(2), 287-292. https://doi.org/10.1007/s00484-016-1210-3

Wang, H., Zhong, S., Tao, Z., Dai, J., \& Ge, Q. (2017). Changes in flowering phenology of woody plants from 1963 to 2014 in North China. International Journal of Biometeorology. https://doi.org/10.1007/s00484-017-1377-2

Way, D. A., \& Montgomery, R. A. (2015). Photoperiod constraints on tree phenology, performance and migration in a warming world. Plant, Cell and Environment, 38(9SI), 1725-1736. https://doi.org/10.1111/pce.12431

Weinberger, J. H. (1950). Chilling requirements of peach varieties. Proceedings of the American society for horticultural science, 56, 122-128. 
Willis, C. G., Ruhfel, B., Primack, R. B., Miller-Rushing, A. J., \& Davis, C. C. (2008). Phylogenetic patterns of species loss in Thoreau's woods are driven by climate change. Proceedings of the National Academy of Sciences of the United States of America, 105(44), 17,029-17,033. https:// doi.org/10.1073/pnas.0806446105

Willis, C. G., Ruhfel, B. R., Primack, R. B., Miller-Rushing, A. J., Losos, J. B., \& Davis, C. C. (2010). Favorable climate change response explains non-native species' success in Thoreau's woods. PLoS One, 5(1), e88781. https://doi.org/10.1371/journal.pone.0008878

Wolkovich, E. M., Cook, B. I., Allen, J. M., Crimmins, T. M., Betancourt, J. L., Travers, S. E., et al. (2012). Warming experiments underpredict plant phenological responses to climate change. Nature, 485(7399), 494-497. https://doi.org/10.1038/nature11014

Zhang, H., Yuan, W., Liu, S., Dong, W., \& Fu, Y. (2015). Sensitivity of flowering phenology to changing temperature in China. Journal of Geophysical Research, 120, 1658-1665. https://doi.org/10.1002/2015JG003112 